Cite as: Daley S, Slade M, Dewey M, Banerjee S A feasibility study of the effects of implementing a staff-level recovery-oriented training intervention older people's mental health services, Aging and Mental Health, in press.

\title{
A feasibility study of the effects of implementing a staff-level recovery-oriented training intervention older people's mental health services
}

Objectives; The concept of recovery has exerted considerable traction in mental health services for adults of working age, but less so in older people's mental health services. The aim of this study was to evaluate the feasibility of a staff-level recovery intervention in older people's mental health services.

Method; The study used a mixed-method pre-post design. The study took place in NHS older people's mental health services, UK. Staff participants were multi-disciplinary mental health team members from the same service. The intervention was a manualised staff-level recovery intervention called the Older Adults Recovery Intervention (OARI). Measurement included the Recovery Knowledge Inventory and the Recovery Attitudes Questionnaire as well as fidelity data and in-depth qualitative interviews.

Results; OARI was delivered to 204 staff in 15 clinical teams. There was a statistically significant change towards improvement in four of the six recovery attitude and knowledge sub-scales. There were positive findings in change in practice at individual level, but not at team level. A number of context barriers were identified leading to the intervention not being delivered as intended. 
Conclusions: Further development of OARI will involve a clearer distinction about the practice implications for service users with dementia versus functional illnesses, a stronger focus on implementation support, more use of evidence in training materials and a tailoring of context to meet professional group training needs. Overall, this study contributes novel data to the evidence base for recovery within older people's mental health services.

Key words: Recovery, clinical practice, older people's mental health services, training 


\section{Introduction}

Recovery in mental health can be described as the subjective process of taking back control of one's life and one's illness, taking personal responsibility for one's own recovery and having optimism for the future (Roberts \& Wolfson, 2004). Recovery relates to a range of outcomes which extend beyond symptom reduction. The concept of recovery has exerted considerable traction in the development of policy and the delivery of services in mental health services for adults of working age worldwide (Canada, 2015; Ministry of Health, 2019; World Health Organization, 2017), but has had much less impact on older people's mental health services.

One possible reason for the relative lack of impact of the recovery movement on older people's mental health services is uncertainty as to how these ideas relate to this specific clinical population, particularly to people with dementia and the paucity of research in this area.

We sought to investigate how recovery related to this population by undertaking qualitative research with service users and carers (Daley, Newton, Slade, Murray, \& Banerjee, 2013) which generated a conceptual framework for recovery for older people with mental health problems, and a linked framework for people with dementia. This confirmed the potential utility of recovery for older adults and also highlighted 
similarities and differences from recovery in adults of working age. Differences for older people included the importance of an established and permanent sense of identity, continuity of social networks, valued roles and activities as coping strategies, as well as mechanisms to reinforce identity. Additional areas of difference for people with dementia related to the stage of dementia and the role of carers in facilitating recovery.

The potential overlap between the philosophy of recovery and personcentred care in dementia (Kitwood, 1997) has been highlighted (McKay, McDonald, Lie, \& McGowan, 2012; Sole \& Read, 2009). Review of the literature reveals the two systems to be complementary to each other as summarised in Table 1 (Gavan, 2011; Hill, Roberts, Wildgoose, Perkins, \& Hahn, 2010; Jeste, 2013; Martin, 2009)

\section{Insert Table 1}

Further the potential for recovery facilitate self-management (Gavan, 2011; Hill et al, 2010); promote choice and positive risk-taking (Martin, 2009) and to support wider cultural change within older people's mental health services (McKay et al., 2012, Woods, 2007) has been identified. Empirical evidence is limited, however a qualitative study of mental health in-patient nurses identified a willingness to adopt recoveryoriented practice, but highlighted the need for specific recovery training (McKenna, Furness, Dhital, \& Ireland, 2014)

Policy and lobby groups age (National Development Team for Inclusion, 2011; Perkins, Hill, Daley, Chappell, \& Rennison, 2016) have encouraged older people's mental health services to adopt practices common delivered within mental health services for adults of working age on the basis that access to user and peer led support, information, and advocacy, all practices linked with recovery have equal value to 
older adults. Furthermore, the discourse of more rights based approach to older people's mental health services using a social model of disability shifts the focus from a deficit based 'clinical' approach, to one which seeks to identify and overcome the barriers (attitudes, expectations, assumptions) that prevent participation in daily life (McGettrick \& Williamson, 2015).

There is however, little in the way of an evidence base for how care practices which support recovery might look like in practice within older people's mental health services. To address this need, we took the findings from our previous qualitative work to service users, carers and staff, along with the existing recovery literature to develop a team-based staff level recovery intervention, the Older Adults Recovery Intervention (OARI). OARI is a manualised educational intervention for staff to increase their prorecovery practice. It is designed for use by staff working in older adults mental health services, in order to improve their recovery knowledge and attitudes, and lead to change in recovery-oriented practice in order to positively influence service user outcomes. The intervention has three components; (i) team recovery training, (ii) action planning and (iii) implementation support. The team recovery training comprises three modules each lasting one day: Promoting Recovery, Maintaining Identity and Enhancing Resilience. Each module is delivered sequentially, with homework from the previous module. There is didactic teaching on each module topic, for example, what is recovery and what is recovery-oriented practice, as well as practice exercises whereby staff share relevant clinical experiences, and consider how the training content can be delivered within routine practice. The action planning (one day) component follows the recovery training, and involves development of a team recovery action plan with specific objectives. Implementation support includes support to developing new pro-recovery 
team processes (such as service user-facing documentation, or service user involvement in care planning), reviewing the team recovery action plan or educational supervision at a team or individual level delivered by the OARI trainer up to six months post action planning day. The specific implementation support differs between teams, and is agreed with each team individually at their action planning day. OARI is delivered by a mental health professional with training experience along with a service user trainer. Additionally, a supporting implementation strategy was developed for the OARI which sought to ensure organisational commitment to the embedding of recovery-oriented practice across the clinical service.

\section{Methods}

The aim of this study was to evaluate the feasibility and effectiveness of the OARI intervention.

The OARI study used a mixed-method pre-post design with two objectives. Objective 1 was to investigate the impact of the intervention on staff attitude and knowledge.

Objective 2 was to assess the reach, acceptability, feasibility of delivery and implementation influences of OARI.

\section{Sample and setting}

The study took place in the older people's mental health services in South-East London in the UK. The clinical service provides secondary mental health services to people over the age of 65 years with mental disorder. In November 2011, the service had an overall caseload of 3,500 service users, and employed 514 staff. 
OARI was delivered to all clinical teams in the service $(n=15)$ comprising ten community mental health teams for older people (CMHTOPs), four acute in-patient units for older people, and one memory service. All staff working within these teams who had clinical contact were invited into the study. All teams were multi-disciplinary, and provided treatment as usual throughout the OARI study.

\section{Measures}

In order to identify suitable measures to assess recovery knowledge and attitude in staff, the following criterion was created, namely that the measure a) had been successfully used with older people, b) assessed at least one outcome domains identified in our intervention (e.g. understanding recovery, maintenance of identity, or resilience), c) was widely used and d) had adequate psychometric properties. A review of available recovery measures at the time, identified the lack of specific measures for older people (Burgess, Pirkis, Coombs, \& Rosen, 2011), and to the authors knowledge, this remains the case. The following two measures were identified as meeting our criterion; the Recovery Attitudes Questionnaire (RAQ-7) and the Recovery Knowledge Inventory (RKI).

The RAQ-7 is a 7-item staff-rated measure of pro-recovery attitudes (Borkin, Steffen, Ensfield, Krzton Wishnick et al, 2000). The RAQ-7 has two sub-scales: Recovery is possible which has 3 items and Recovery is difficult which has 3 items. Each item is scored on a 5-point Likert scale, ranging from 1 (strongly disagree) to 5 (strongly agree). The sub-scale scores are the total of the item scores, ranging from 4 to 20 for Recovery is possible and 3 to 15 for Recovery is difficult, with higher scores indicating higher levels of pro-recovery attitude. This measure has acceptable internal consistency for the two subscales Recovery is possible $(\alpha=0.66)$ and Recovery is difficult ( $\alpha=$ 0.64), and adequate test-retest reliability (0.67) (Borkin et al., 2000). 
The RKI is a 20-item measure of recovery knowledge (Bedregal, O'Connell, \& Davidson, 2006) . There are four sub-scales: roles, non-linearity (of the recovery process), self-definition and expectations (regarding recovery). Each sub-scale has 4 items, and each item is scored on a 5-point Likert scale ranging from 1 (strongly disagree) to 5 (strongly agree). The total sub-scale scores are the mean of the total item scores within that sub-scale, ranging from 1 to 5 , with higher scores indicating higher levels of recovery knowledge. This measure has adequate internal consistency for three of the four subscales: Roles $(a=0.81)$, Non-linearity $(a=0.70)$ and Self-definition $(a=0.63)$. The Expectations subscale $(a=0.47)$ is recognised as having poor internal consistency (Bedregal et al., 2006) .

\section{Procedure}

NHS Research Ethics approval was obtained North West London REC 1 (Ref: 09/H0722/66). The planned delivery of OARI was agreed sequentially on the basis of geography and organisational readiness for OARI, assessed by the service director as the absence of any substantial service delivery difficulties. OARI was delivered between March 2010 and December 2011. A more comprehensive evaluation involving qualitative interviews took place in the final six teams to receive the OAR intervention between March and November 2011.

Prior to delivery of the recovery training component of the intervention, the researchers (lead author and a research worker) obtained written informed consent from staff and obtained baseline staff measures (RKI \& RAQ-7). Staff participants who completed all three training modules were asked to re-complete measures at the end of the final module. 
One month after delivery of the first two components of the intervention (training and action planning day) and six months after the final component (implementation support), an in-depth qualitative interview with staff members from each of the final six teams about their experience of OARI was completed by the lead author. Potential participants were purposively sampled in order to involve staff members judged by trainers either to have actively participated (actively contributed within the training and towards to the team recovery action) or to have disengaged from the experience (lack of active contribution within training and action planning day). Additionally, interviews with the trainers took place. A topic guide was developed and used to investigate (i) the experience of the intervention, and (ii) whether pro-recovery change in their own or team practice had taken place, and what factors had affected change or lack of change.

To assess feasibility of delivery, a fidelity assessment was completed from review of the training data which included; attendance records and action plans, as well as discussion with team leaders (with regards to implementation and progress).

\section{Analysis}

Quantitative analysis used SPSS 18. Advice was sought from the authors of each measure as how to deal with missing data, who indicated that average values should be imputed. Missing items did not exceed $20 \%$ on any of the measures completed, so none were excluded from the analysis. 
First overall improvement in attitude (RAQ-7) and knowledge (RKI) following delivery of the training component of the OAR intervention was tested using a paired sample t-test. No adjustment for multiple testing was made, as each sub-scale was of interest, and the implications for each were different (Cook \& Farewell, 1996; Perneger, 1999).

We used a mixed effects model to analyse change on each of the six measures. Each model regressed the change score on the corresponding baseline value and on staff group as a categorical variable with seven levels. We included team as a random effect to allow for clustering within team. Analysis was conducted in R version 3.5.1 using the nlme version 3.1-137 and metafor version 2.0-0 packages.

Third, reach was assessed by calculating differences in receipt between professions. This was undertaken by assessing completion of the RKI and RAQ-7, and comparing those who received one or more module to those who did not receive any of the modules of the team recovery training, using the Chi-square test.

Qualitative interviews were undertaken by the lead author (SD) and a research assistant. Each interview was during working hours, in a NHS setting, and took between 30-45 minutes. Each interview was audio recorded, transcribed verbatim, and analysed by SD using thematic analysis to identify pertinent topics within the data. Thematic analysis was chosen as a pragmatic decision suited to health services research, made on the basis of the weighting given to the quantitative findings within the OARI study, and because thematic analysis was a more appropriate level of complexity than other more theoretically driven 
approaches. A topic guide (see supplementary information) explored the OARI experience, and sought to assess whether pro-recovery change at an individual or team level had taken place, and what factors had affected change or lack of change.

Analysis involved four stages: familiarisation with the data, development of a thematic (coding) framework, indexing and sorting the data and reviewing of data extracts (Spencer, Ritchie, O'connor, Morrell, \& Ormston, 2014). First the lead author (SD) re-read the transcripts to familiarise herself with the content. Second, SD reviewed the first two transcripts of each round of interviews and identified meaningful segments of text within each transcript which she labelled with descriptive codes. The codes identified within the first two transcripts were used to develop an initial coding framework for acceptability and context. To support rigour in the process, two transcripts in each round of interviews were also coded by an independent researcher and two coding frameworks were agreed. Reflexivity was ensured by supervision with an experienced qualitative researcher. The frameworks were then used to code the remaining transcripts. A computer software package, NVivo 8 (QSR International, 2008) was used to help organise the data.

\section{Results}

OARI was delivered to 204 staff in 15 clinical teams, of which 177 staff received all training components of the intervention.

Qualitative interviews were conducted with 12 staff participants (5 nurses, 3 occupational therapists, 2 social workers, 1 psychiatrist, 1 psychologist) and 4 trainers ( 2 nurses, 2 service user trainers).

\section{Objective 1: Staff attitude and knowledge}


Art therapy was removed from the analysis to ensure anonymity for the sole art therapist who received the intervention, leaving 176 paired staff measures. Changes in staff attitude (RAQ-7) and knowledge (RKI) at baseline and at the end of recovery training component of the intervention are shown in Table 2.

Insert Table 2

There was positive changes in all scales, with statistically significant change towards improvement in four of the six subscales: RAQ-7 sub-scale 1 (Recovery is possible), and RKI sub-scales 1 (Roles), 2 (Non-linearity) and 3 (Self-definition).

The results from the mixed effects model for the RAQ-7 is shown in Table 3

Insert Table 3

The intercept is the estimated change for the reference group (Health Care Assistant) for a person scoring 16 (sub-scale 1) and zero (sub-scale 2) on the baseline measure and the other coefficients show the difference in the change score for that staff group. There is no overall effect of staff group on sub-scale one (Recovery is possible), but an overall effect of staff group on sub-scale 2 (Recovery is difficult) with Occupational Therapists showing most change and social workers and psychologists the least.

The results from the mixed effects model for the RKI is shown in Table 4

Insert Table 4 
The intercept is the estimated change for the reference group (Health Care Assistant) for a person scoring 3 on sub-scales 1, 2 and 4, and 4 on subscale 3 , on the baseline measure and the other coefficients show the difference in the change score for that staff group.

There is an overall effect of staff group for sub-scales 1, 2, and 3. In subscale 1 , health care assistants and support workers show least change, with the other groups being more or less equal. For sub-scale 2, occupational therapists, psychologists and social workers show most change with the other groups being more or less equal. For sub-scale 3, nurses and occupational therapists show most change, the other groups are all more or less equal. For sub-scale 4, no overall effect of staff group can be seen.

Overall, staff (professional) group membership appeared to be a factor in the acquisition of recovery knowledge and some impact on attitude.

\section{Objective 2: Reach, acceptability, feasibility and implementation influences}

\section{Reach}

The total workforce was 248 staff, and of these 203 (81\%) staff received all or part of the team recovery training component of the OARI, with $176(71 \%)$ receiving all of the training modules (3 days) and 27 (11\%) receiving part of it (1-2 days), and 45 (18\%) receiving none of it. 
Receipt of the team recovery training component of OARI by profession for the 203 staff participants was compared to overall workforce profile of eligible staff in Table 5.

\section{Insert Table 5}

With the exception of psychiatrists, receipt of the full team recovery training component of the OAR intervention was $70 \%$ or over for eligible staff. The percentage of psychiatrists and psychologists not receiving all of the training was higher than the rate for other professional groups, but this did not achieve statistical significance $\left(X^{2}=3.18\right.$, $5 \mathrm{df}, \mathrm{p}=0.67)$. Reach for all professional groups apart from psychiatrists was acceptable.

\section{Acceptability}

Five over-arching themes influencing acceptability were identified from the analysis of the qualitative interviews with staff and trainers. These were: (i) training dyad (ii) content (iii) challenging assumptions, (iv) team factors and (v) wider external influences such as change fatigue and uncertainty about future role/services. These themes are summarised in Table 6.

\section{Insert Table 6}

Overall, opinion about the acceptability of the intervention was mixed. Components of the intervention which appeared to enhance acceptability included involvement of a service user trainer, the specific fit between trainers and team, and the skill level of the trainers. Components which appeared to decrease acceptability included using a team approach to the training (due to varying training needs of different professions), a 
perceived lack of evidence to support recovery, and difficulties by the trainers in some instances in not being able to challenge existing assumptions (about the degree to which team practice was already recovery-oriented) without increasing defensiveness. Contextual factors influencing acceptability included team culture, the role of key individuals (positive and negative) within the team, and wider external influences impacting upon the timing of the intervention (change fatigue, and wider uncertainty about the future).

\section{Feasibility of delivery}

Four aspects of fidelity were assessed from the training data against agreed targets; attendance, delivery of the intervention, obtaining team ownership and delivery of the team implementation strategy. A summary of the findings for each is shown in Table 7.

\section{Insert Table 7}

Whilst overall attendance was acceptable, OARI was only partially delivered as intended, with only 9 of the 15 teams (56\%) receiving the training component of the intervention as a whole team, with remaining teams receiving the intervention with other teams) as well as limited delivery of implementation support and team action planning (both 60\%).

\section{Implementation}

Analysis of the qualitative interviews identified four themes impacting upon the implementation of recovery-oriented practice at team level, variable individual practice 
change, lack of a team approach to changing practice, barriers and facilitators. These themes are summarised in Table 8.

Insert Table 8

Barriers to implementation included a lack of focus on recovery within the team and wider service, lack of re-enforcement by senior managers, pressure on time and wider service changes. (Moved to table 7)

Facilitators in changing practice included team ownership; specifically by maintaining a team focus and pro-recovery champions, as well as the fit with professional identity, and use of practice support tools.

\section{Discussion}

The aim of this study was to evaluate the feasibility and effectiveness of the staff-level OARI intervention which was delivered to 15 clinician teams.

Our OARI feasibility study shows mixed findings. As this was a feasibility study so the evaluation was not powered to detect statistically significant changes. However, in terms of staff outcomes, the positive changes in four of the six recovery attitude and knowledge sub-scales provides encouraging preliminary evidence of effectiveness. There were positive findings relating to the feasibility of delivering the programme and reported change in practice at individual but not team level. However, there were mixed findings about acceptability, and this led to the intervention was not delivered as 
intended. Context barriers included the lack of service focus on recovery, in particular external implementation support, and the impact of wider service changes. Finally, it is possible that staff who received the intervention were already delivering practice which could be deemed as recovery-oriented.

\section{Evaluation and further development of OARI}

Five areas for further development of OARI are indicated from this evaluation.

First the scope of OARI was very broad, and sought to address recoveryoriented practice in relation to a wide range of service users. This may have made the specific practice implications insufficiently defined for staff. Whilst it is recognised that recovery is primarily an individual process, there is an evolving evidence about practices (in services for working age adults which can help, rather than hinder recovery (Mike Slade et al., 2014). In optimising OARI and in other work to develop recoveryorientated practice in older people's mental health services, there is a need to be specific about actions that might be taken for those with dementia and functional illness and how these might differ.

Second, whilst the training component of the intervention was delivered successfully overall, fidelity was more problematic. OARI was developed as a teambased intervention and not all team members participated. Implementation support was also patchy. Lack of implementation support was identified by staff as reducing the team focus on recovery. This is consistent with the literature on the importance of 'team reflexivity': activities which encourage reflection, questioning and action learning in order to support change and adaptation (West, 1996). The challenge of supporting the 
transfer of learning into practice has also been identified in other staff-level recovery interventions (M Slade et al., 2015; Uppal, Oades, Crowe, \& Deane, 2010). This suggests that OARI needs a sharper focus on implementation support to embed and sustain behaviour change.

Third, we did not investigate whether OARI has an impact on service user outcomes, and further work is needed in this area. We observed statistically significant changes in staff attitudes and knowledge rather than patient outcomes and the relationship between the two is unclear. In terms of measurement of patient outcomes, currently there are no recovery measures specifically designed for older people. It would be useful to have a measure of recovery developed for older people including both self and proxy reports for use in any future evaluation.

Fourth, professional group membership impacted on outcome. Two issues relating to professional group were identified. First, there was a lower level of reach to psychiatrists. The consequent impact of psychiatrists not engaging in the intervention was identified in the qualitative interviews by non-psychiatrists as a factor which undermined the implementation of recovery-practice within teams. This is consistent with other studies of recovery training, where lack of engagement by psychiatrists in recovery training has acted as a barrier to subsequent practice change (Gilburt, Slade, Bird, Oduola, \& Craig, 2013). Second, in terms of the impact of professional group membership upon outcomes, differences between professions were apparent at baseline, with increased homogeneity within professional groups. This suggests that both the acquisition of new knowledge and attitude change might be more heavily influenced by professional norms and philosophy rather than team membership. This has implications 
for how change in recovery attitude and knowledge might best be achieved in practice, and whether different approaches are required for each. There was considerable variation in knowledge outcomes by professional group, with nurses generally achieving higher mean change score compared to other professional groups. One conclusion might be that the OARI was appropriately tailored towards nursing as the largest workforce professional group (57\% of the eligible staff population) at the cost of benefit for other professional groups. The results suggest the need for a more nuanced approach within the intervention, with the use of both team and profession-specific components

Fifth, the lack of available evidence supporting about recovery for users of older people's mental services OPMHS affected the acceptability of the intervention. This is in keeping with concerns expressed about recovery-oriented practice within mental health services for adults of working age (Davidson, O'Connell, Tondora, Styron, \& Kangas, 2006). If there were data on older adults similar to the evidence from longitudinal studies, such as the Vermont Longitudinal study with people with psychosis, this could have been used to challenge these concerns. The Vermont Longitudinal Research project was a 32 year study looking at long-term outcomes for 269 service users discharged from institutions without planned mental health aftercare in Vermont. These have shown that clinical recovery from psychosis is much higher than previously considered, with $68 \%$ of participants not demonstrating symptoms of schizophrenia and exhibiting normal functioning (Harding, Brooks, Ashikagat, Strauss, \& Brier, 1987). 


\section{Limitations and strengths}

There are three main limitations to this study. First the non-randomised delivery of the intervention limits inference, as more stable teams may have entered the study earlier. This means that there may have been order effects which could have systematically impacted on outcome, such as improved responsiveness to training. Second, attitude and knowledge change could have been more robustly investigated. Pre-post measures were only assessed in participants receiving all of the recovery training. This means that a full dose-response relationship could not be directly investigated and also that bias could have been introduced into the final sample due to self-selection. Third, adjustment was not made for multiple testing, which increases the risk of a Type I error.

There are however strengths to this study. We have assessed both the feasibility and effectiveness of a staff level recovery-intervention within 15 older people's mental health teams. We believe this is the first such study to have been completed. As such the data presented here, while limited, makes a contribution towards building the evidence base in this area of policy and practice importance. It is also positive that this study took place in the context of routine service delivery with a broad range of staff, and therefore the findings can be seen as both representative and generalizable. Finally, the staff recruitment and outcome data are encouraging. The intervention was delivered to 15 clinical teams, and of 249 eligible staff, 204 (82\%) received part or all of the team recovery training, with $177(71 \%)$ receiving all of the training. The changes in prorecovery attitudes in staff are positive, their link to improving patient care and outcomes needs further investigation

\section{Conclusion}


The OARI feasibility study contributes usefully to the evidence base for recovery within older people's mental health services and how this might be implemented. A staff level intervention has been tested and allows us to develop further the intervention for future wide scale evaluation of its impact on staff and service users. The data from the evaluation provide information about the acceptability and utility of elements of the intervention that would allow the design of a more definitive evaluation, such as a cluster randomised controlled trial of the next iteration of OARI. It also makes clear that further research to understand both the experience of recovery for different groups of service users, as well as the practice implications for staff would be valuable as would the development of instruments that can measure recovery in older people with functional illness and dementia with acceptable validity and reliability.

\section{References}

Bedregal, L., O'Connell, M., \& Davidson, L. (2006). The Recovery Knowledge Inventory: assessment of mental health staff knowledge and attitudes about recovery. Psychiatric Rehabilitation Journal, 30(2), 96-103. 
Borkin, J., Steffen, J., Ensfield, L., Krzton, K., Wishnick, H., Wilder, K., \& Yangarber, N. (2000). Recovery Attitudes Questionnaire: Development and evaluation. Psychiatric Rehabilitation Journal,, 24(2), 95.

Burgess, P., Pirkis, J., Coombs, T., \& Rosen, A. (2011). Assessing the value of existing recovery measures for routine use in Australian mental health services. Australian and New Zealand Journal of Psychiatry, 45(4), 267-280.

Canada, M. H. C. o. (2015). Recovery Guidelines. Ottawa.

Cook, R. J., \& Farewell, V. T. (1996). Multiplicity Considerations in the Design and Analysis of Clinical Trials. Journal of the Royal Statistical Society. Series A (Statistics in Society), 159(1), 93-110. doi:10.2307/2983471

Daley, S., Newton, D., Slade, M., Murray, J., \& Banerjee, S. (2013). Development of a framework for recovery in older people with mental disorder. International Journal of Geriatric Psychiatry, 28(5), 522-529.

Davidson, L., O'Connell, M., Tondora, J., Styron, T., \& Kangas, K. (2006). The top ten concerns about recovery encountered in mental health system transformation. Psychiatr Serv, 57. doi:10.1176/ps.2006.57.5.640

Gilburt, H., Slade, M., Bird, V., Oduola, S., \& Craig, T. K. (2013). Promoting recoveryoriented practice in mental health services: a quasi-experimental mixedmethods study. BMC psychiatry, 13(1), 1.

Harding, C., Brooks, G., Ashikagat, Strauss, J., \& Brier, A. (1987). The Vermont Longitudinal study of persons with severe mental illness, I. Methodology, study sample, and overall status 32 years later. American Journal of Psychiatry, 144, 717-726.

Kitwood, T. (1997). The Person Comes First. In. Buckingham: Open University Press.

McGettrick, S., \& Williamson, T. (2015). Dementia, rights and the social model of disability. London Mental Health Foundation.

McKay, R., McDonald, R., Lie, D., \& McGowan, H. (2012). Reclaiming the best of the biopsychosocial model of mental health care and 'recovery' for older people through a 'person-centred' approach. Australasian Psychiatry, 20(6), 492-495. doi:10.1177/1039856212460286

McKenna, B., Furness, T., Dhital, D., \& Ireland, S. (2014). Recovery-Oriented Care in Older-Adult Acute Inpatient Mental Health Settings in Australia: An Exploratory Study. Journal of the American Geriatrics Society, 62(10), 1938-1942. doi:10.1111/jgs. 13028

Ministry of Health. (2019). Office of the Director of Mental Health and Addiction Services Annual Report 2017. Wellington.

National Development Team for Inclusion. (2011). Long Time Coming - achieving age equality in mental health services. Part 2. Retrieved from Bath:

Perkins, R., Hill, L., Daley, S., Chappell, M., \& Rennison, J. (2016). 'Continuing to be me' Recovering a life with a Diagnosis of Dementia. Retrieved from Nottingham:

Perneger, T. V. (1999). Adjusting for multiple testing in studies is less important than other concerns. BMJ, 318(7193), 1288. doi:10.1136/bmj.318.7193.1288a

Roberts, G., \& Wolfson, P. (2004). The rediscovery of recovery: open to all. Advances in Psychiatric Treatment, 10(1), 37-48.

Slade, M., Amering, M., Farkas, M., Hamilton, B., O'Hagan, M., Panther, G., . . . Whitley, R. (2014). Uses and abuses of recovery: implementing recovery-oriented practices in mental health systems. World Psychiatry, 13(1), 12-20.

Slade, M., Bird, V., Clarke, E., Le Boutillier, C., McCrone, P., Macpherson, R., . . . Leamy, M. (2015). Supporting recovery in patients with psychosis using adult mental health teams (REFOCUS): a multi-site cluster randomised controlled trial. Lancet Psychiatry, 2, 503-514.

Sole, K., \& Read, L. (2009). Person-centred care and recovery. In M. H. Foundation (Ed.), Older People's Mental Health Today: A handbook. London: OLM-Pavilion. 
Spencer, L., Ritchie, J., O'connor, W., Morrell, G., \& Ormston, R. (2014). Analysis in Practice. In Ritchie J, J. Lewis, C. McNaugthon Nicholls, \& R. Ormston (Eds.), Qualitative Research Practice. London: Sage.

Uppal, S., Oades, L. G., Crowe, T. P., \& Deane, F. P. (2010). Barriers to transfer of collaborative recovery training into Australian mental health services: implications for the development of evidence-based services. Journal of Evaluation in Clinical Practice, 16(3), 451-455.

West, M. (1996). Reflexivity and work group effectiveness: A conceptual integration. Chichester: John Wiley \& Sons, Ltd.

World Health Organization. (2017). Promoting recovery in mental health and related services: - WHO Quality Rights training to

act, unite and empower for mental health. Geneva: World Health Organization 
Table 1 Overlap between person-centred care and recovery

\begin{tabular}{lll}
\hline Personhood Overlap with Recovery & Identified by
\end{tabular}

needs

Attachment Significance of relationships with others $\quad$ Hill et al, 2010

Identity Knowing the person

McKay et al, 2010

Seeing beyond the diagnosis

Sole and Reed,

2009

Revised sense of identity

Adams, 2010

Inclusion Impact of exclusion for people with

Gavan, 2011

dementia as well as those with serious

Sole and Read,

mental illness

2009

Support to enable on-going community Hill et al, 2010

dwelling and inclusion

Occupation Importance of meaningful activities

Sole and Reed,

2009

Comfort Seeing the world from the perspective of Hill et al, 2010

the person with dementia

Use of life history to understand what is $\quad$ Martin, 2009

important to the person 
Table 2 Pre-post training change in RAQ-7and RKI $(n=176)$

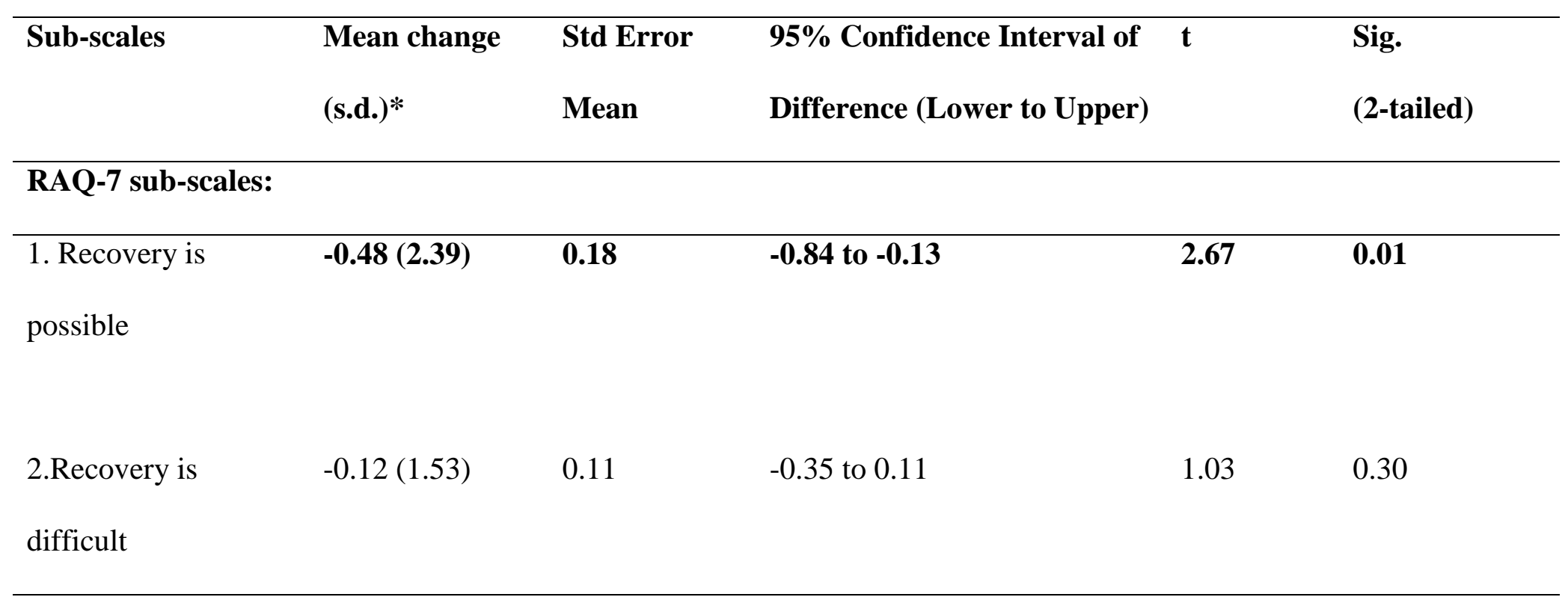

RKI sub-scales:

\begin{tabular}{llllll}
\hline 1. Roles & $-\mathbf{0 . 3 5}(\mathbf{0 . 6 2})$ & $\mathbf{0 . 0 5}$ & $\mathbf{- 0 . 4 4}$ to -0.25 & $\mathbf{7 . 3 5}$ & $\mathbf{0 . 0 0}$ \\
& & & & & \\
& & & & \\
2. Non-linearity & $-\mathbf{0 . 2 7}(\mathbf{0 . 5 8})$ & 0.04 & -0.36 to -0.18 & 6.22 & 0.00 \\
\hline
\end{tabular}


3.Self definition

$-0.21(0.58)$

0.04

-0.30 to -0.13

0.07

-0.25 to 0.03

$-053$

0.13

Negative scores show positive change, bold denotes $p<0.05$ 
Table 3 Summary of the mixed effects model for RAQ-7

\begin{tabular}{|c|c|c|c|c|c|c|}
\hline RAQ-7 Sub-scales & $\begin{array}{l}\text { Reco } \\
\text { sub-s }\end{array}$ & $\begin{array}{l}\text { ary is po } \\
\text { ale } 1\end{array}$ & sible & $\begin{array}{l}\text { Reco } \\
\text { sub-s }\end{array}$ & ary is di & îcult \\
\hline Staff group & est. & lower & upper & est. & lower & upper \\
\hline Intercept & -0.37 & -1.27 & 0.53 & -0.14 & -0.60 & 0.31 \\
\hline Baseline & -0.60 & -0.76 & -0.44 & -0.64 & -0.77 & -0.51 \\
\hline Nurse & 0.88 & -0.04 & 1.80 & 0.49 & -0.05 & 1.03 \\
\hline OT & 0.93 & -0.37 & 2.23 & 1.07 & 0.33 & 1.81 \\
\hline Psychiatrist & 0.79 & -0.84 & 2.41 & 0.35 & -0.58 & 1.28 \\
\hline Psychologist & 0.96 & -0.76 & 2.68 & -0.17 & -1.14 & 0.81 \\
\hline Social Worker & 0.03 & -1.39 & 1.46 & -0.21 & -0.99 & 0.58 \\
\hline Support Worker & 0.69 & -0.58 & 1.95 & 0.69 & -0.02 & 1.40 \\
\hline Staff group likelihood & Ratio & Df & $\mathbf{P}$ & Ratio & Df & $\mathbf{p}$ \\
\hline ratio test & 5.02 & 6 & 0.54 & 14.49 & 6 & 0.02 \\
\hline
\end{tabular}


Table 4 Summary of the mixed effects model for RKI

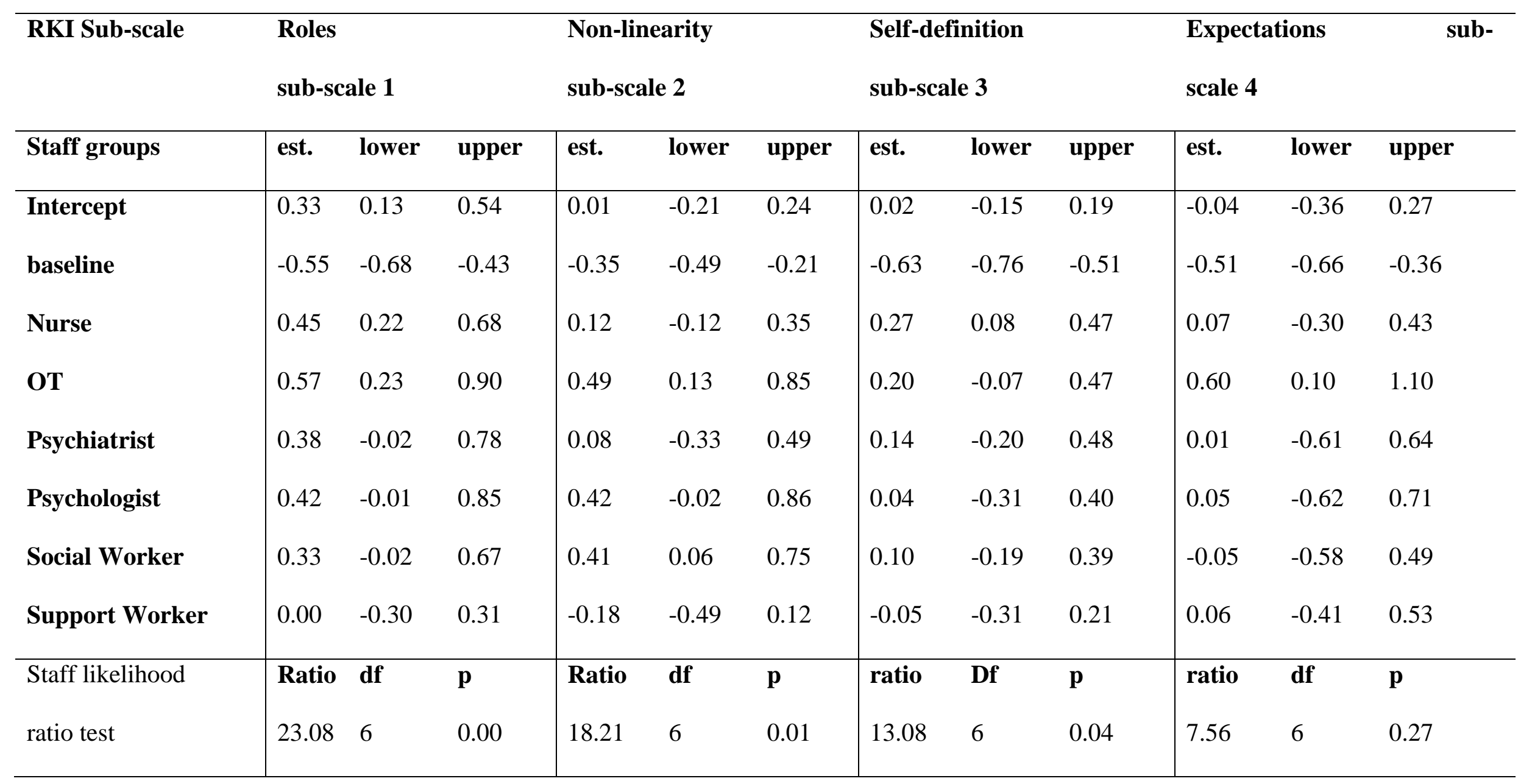


Table 5 Receipt of training by profession

\begin{tabular}{lllll}
\hline Staff group & Received & Received none & Staff eligible for & Reach for each \\
& $\begin{array}{l}\text { all/part of the } \\
\text { training }\end{array}$ & of the training & OARI (\% of & staff group (\%) \\
& 120 & 18 & $138(58)$ & $87 \%$ \\
\hline Nursing & 21 & 4 & $25(10)$ & $84 \%$ \\
Occ Therapist & 13 & 14 & $27(10)$ & $48 \%$ \\
Psychiatrist & 10 & 4 & $14(5)$ & $71 \%$ \\
Psychologist & 16 & 4 & $20(8)$ & $80 \%$ \\
Social Worker & 23 & 1 & $24(9)$ & $96 \%$ \\
Support worker & 23 & $\mathbf{2 4 8}$ & - \\
\hline Total & $\mathbf{2 0 3}$ & & & \\
\hline
\end{tabular}


Table 6 Factors influencing Acceptability

\begin{tabular}{|c|c|c|}
\hline Theme & Includes & Example \\
\hline Training dyad & $\begin{array}{l}\text { Value of having a skilled } \\
\text { service user trainer, fit } \\
\text { between trainers and team } \\
\text { (positive or negative), high } \\
\text { skill level of the trainers }\end{array}$ & $\begin{array}{l}\text { It became more magnified as the days } \\
\text { progressed so by the third day it did feel } \\
\text { somewhat adversarial and I think there } \\
\text { was a degree of detachment from the } \\
\text { day...we never got past that } \\
\text { disagreement' (No.3, Nurse) } \\
\text { 'What I found really useful on a } \\
\text { personal level was thinking about risk } \\
\text { and how we manage risk, and I think } \\
\text { that worked really well in the training } \\
\text { because we have X's (service user } \\
\text { trainer) personal experience which was } \\
\text { really powerful' (No } 1 . \text { OT) }\end{array}$ \\
\hline Content & $\begin{array}{l}\text { Mixed opinion about the } \\
\text { content, length of training, } \\
\text { Different learning } \\
\text { preferences, challenge of } \\
\text { training to a mixed group of } \\
\text { professionals (pitched too } \\
\text { low for some staff), desire } \\
\text { for a stronger evidence base } \\
\text { within the content of the }\end{array}$ & $\begin{array}{l}\text { 'But it's very difficult when you've got a } \\
\text { mixture of disciplines and grades and } \\
\text { you know, you have got to be careful } \\
\text { where you pitch it, you can't pitch it for } \\
\text { the consultant...I think a lot of the } \\
\text { exercises we did on communication, I } \\
\text { think are too basic' (No.6, Team } \\
\text { Leader) }\end{array}$ \\
\hline
\end{tabular}




\begin{tabular}{|c|c|c|}
\hline & training & $\begin{array}{l}\text { 'I think it was clear what recovery } \\
\text { meant as a concept and I think people } \\
\text { began to feel frustrated when there was } \\
\text { direct questions asked what was the } \\
\text { evidence base and where had the } \\
\text { models that were going to be used been } \\
\text { developed from and those questions } \\
\text { couldn't be answered (No.4 Nurse) }\end{array}$ \\
\hline $\begin{array}{l}\text { Challenging } \\
\text { assumptions }\end{array}$ & $\begin{array}{l}\text { Need to challenge existing } \\
\text { staff assumptions that 'We } \\
\text { are doing recovery } \\
\text { already' seen as an } \\
\text { essential component of the } \\
\text { training by both trainers and } \\
\text { staff and recipients. The } \\
\text { challenge of doing so } \\
\text { without increasing } \\
\text { defensiveness, need to build } \\
\text { on existing good practice }\end{array}$ & $\begin{array}{l}\text { 'One of the social workers started } \\
\text { saying 'oh this is our social work } \\
\text { philosophy and this is where we come } \\
\text { from and we 're always doing this' and } \\
\text { couldn't quite see where X (the trainer) } \\
\text { was coming from and I think if we'd } \\
\text { actually been able to spend more time } \\
\text { expanding that, I think that would have } \\
\text { helped.' (No.5, Nurse) } \\
\text { The resistance was absolutely enormous } \\
\text { and it was like 'this is best practice, this } \\
\text { is what we do, why are you suggesting } \\
\text { that there's a better way of doing it' and } \\
\text { never got to that stage really... The fact }\end{array}$ \\
\hline
\end{tabular}




\begin{tabular}{|c|c|c|}
\hline & & $\begin{array}{l}\text { is I don't think that, our team takes very } \\
\text { well to being told how to change or it } \\
\text { gets quite defensive about kind of } \\
\text { thinking about ways they can change } \\
\text { practice really.' (No.1, OT) }\end{array}$ \\
\hline Team factors & $\begin{array}{l}\text { Team culture, key } \\
\text { individuals (having a } \\
\text { negative or positive impact), } \\
\text { whether team has a } \\
\text { traditional or more } \\
\text { innovative model of care } \\
\text { delivery, need for a team } \\
\text { approach to recovery- } \\
\text { oriented practice }\end{array}$ & $\begin{array}{l}\text { 'I think this is an innovative team, I } \\
\text { think I have clinicians that are very } \\
\text { keen on research, they're very keen on } \\
\text { moving forward, they like challenging } \\
\text { norms, they're very creative and they } \\
\text { can see the benefits and things, they're } \\
\text { not rigid in their thinking.' (No.2, Team } \\
\text { leader) } \\
\text { 'The over-riding group dynamic was } \\
\text { negative and so you end up feeling very } \\
\text { the team she spoke about recovery and I } \\
\text { negative and exhausted like we did and } \\
\text { interesting, not in the training but } \\
\text { rained.' ( Service user trainer) }\end{array}$ \\
\hline
\end{tabular}




\begin{tabular}{|c|c|c|}
\hline & & $\begin{array}{l}\text { said to her 'we do it already' and she } \\
\text { said 'you'll be surprise how much we } \\
\text { don't do' and then she talked about her } \\
\text { own experiences at X (another NHS } \\
\text { Trust with a pro-recovery culture) } \\
\text { where service users are on interview } \\
\text { panels.( No.4 Nurse) }\end{array}$ \\
\hline $\begin{array}{l}\text { External } \\
\text { influences/ } \\
\text { Timing }\end{array}$ & $\begin{array}{l}\text { Timing, change fatigue } \\
\text { Uncertainty about the future } \\
\text { of the team, Job insecurity }\end{array}$ & $\begin{array}{l}\text { '(Staff believe that) if you work with } \\
\text { people pro-actively in a recovery } \\
\text { agenda and that actually you'll be } \\
\text { doing yourself out of a job you know. 'If } \\
\text { I reduce my caseload by doing what } \\
\text { you're telling me to do' and that's the } \\
\text { hidden agenda behind the training.' } \\
\text { (Service user trainer,) } \\
\text { 'I also did try to express to X (the } \\
\text { trainer) that this was a difficult time and } \\
\text { an unfortunate time that giving the team } \\
\text { had such concern regarding its own } \\
\text { future. It felt, I think it felt that this } \\
\text { wasn't the best time. The team didn't } \\
\text { feelogist) }\end{array}$ \\
\hline
\end{tabular}


Table 7 Fidelity Assessment

\begin{tabular}{|c|c|c|}
\hline Fidelity domain & Achieved & If no, proportion delivered / implemented \\
\hline \multicolumn{3}{|l|}{ Attendance } \\
\hline $90 \%$ of the team to receive at least one training module & No & $90 \%$ of staff in 5 teams (33\%) received 1 training module \\
\hline $75 \%$ of the team to receive all of the training modules & No & $75 \%$ of staff in 5 teams (33\%) received all training modules \\
\hline \multicolumn{3}{|l|}{ Delivery of the intervention } \\
\hline All staff to receive training modules $1,2,3$ & No & $93 \%$ of teams $(n=14)$ received modules $1-3$ \\
\hline All staff to receive training modules 1,23 as a team & No & Only $53 \%$ of teams $(n=8)$ received modules as a team \\
\hline $\begin{array}{l}\text { All training modules to be delivered as per manualised } \\
\text { package }\end{array}$ & Yes & \\
\hline $\begin{array}{l}\text { All training to be delivered by a dyad of staff/service user } \\
\text { trainer }\end{array}$ & Yes & \\
\hline \multicolumn{3}{|l|}{ Obtaining Team Level Ownership: } \\
\hline Team to identify three areas of practice & Yes & \\
\hline $\begin{array}{l}\text { Team to develop an action plan with objectives and } \\
\text { timescales }\end{array}$ & No & $60 \%$ of teams $(n=9)$ developed a recovery action-plan \\
\hline
\end{tabular}




\begin{tabular}{|l|l|l|}
\hline All teams to receive implementation support & No & $60 \%$ of teams (n=9) received implementation support \\
\hline Delivery of the implementation strategy & No & Contracting meeting with team and service in 14 (93\%) of teams \\
\hline Preparatory meeting with team/ service managers & Yes & All teams received briefing session \\
\hline $\begin{array}{l}\text { All teams to have briefing session } \\
\text { planning day }\end{array}$ & No & $\begin{array}{l}\text { Service manager attended action planning day in 93\% of teams } \\
(\mathrm{n}=14)\end{array}$ \\
\hline
\end{tabular}


1 Table 8 Factors influencing Implementation

\begin{tabular}{|c|c|c|}
\hline Theme & Includes & Example \\
\hline $\begin{array}{l}\text { variable } \\
\text { individual } \\
\text { change }\end{array}$ & $\begin{array}{l}\text { Change at an individual } \\
\text { level, including care } \\
\text { planning, communication } \\
\text { with service users, working } \\
\text { more collaboratively with } \\
\text { service users and focusing } \\
\text { more on wellness. }\end{array}$ & $\begin{array}{l}\text { 'It's totally changed the way I do my } \\
\text { care plan now. It's really changed. I've } \\
\text { got a lady,,,she's got a quite a long } \\
\text { care plan but we did it, and she said to } \\
\text { me, she said thank you X (participant's } \\
\text { name) she said, you've really thought } \\
\text { about what I said, it was about } 14 \\
\text { different things but you know she } \\
\text { obviously wanted them, she just felt } \\
\text { she'd been heard as well.' (No.11, } \\
\text { Nurse) }\end{array}$ \\
\hline $\begin{array}{l}\text { lack of a team } \\
\text { approach }\end{array}$ & $\begin{array}{l}\text { Lack of focus on recovery } \\
\text { by the team, limited } \\
\text { opportunities to share } \\
\text { practice or review } \\
\text { processes, }\end{array}$ & $\begin{array}{l}\text { 'I don't know how anyone is getting on } \\
\text { with that (life history work) ... I wonder } \\
\text { if anybody is doing the (well-being) } \\
\text { care plans?' (No. 12, OT) }\end{array}$ \\
\hline Barriers & $\begin{array}{l}\text { Lack of re-enforcement by } \\
\text { senior managers, pressure } \\
\text { on time and wider service } \\
\text { changes }\end{array}$ & $\begin{array}{l}\text { '(Staff) get bogged down in their } \\
\text { caseload and their work, and it's time } \\
\text { because (to do recovery) 'you've got to } \\
\text { go out and spend another session with }\end{array}$ \\
\hline
\end{tabular}




\begin{tabular}{|c|c|c|}
\hline & & $\begin{array}{l}\text { your service user and do a care plan.' } \\
\text { (No.10, Nurse) }\end{array}$ \\
\hline Facilitators & $\begin{array}{l}\text { Maintaining a team focus } \\
\text { and pro-recovery } \\
\text { champions, fit with } \\
\text { professional identity, use of } \\
\text { practice support tools }\end{array}$ & $\begin{array}{l}\text { 'I think have regular meetings, } \\
\text { quarterly meetings, having designated } \\
\text { time in multi-disciplinary team meeting } \\
\text { to think about it, to reflect on the } \\
\text { practice.' (No.9, Team leader) }\end{array}$ \\
\hline
\end{tabular}

